\title{
Quaternary seismic stratigraphic sequence of Nansha sea area and its geological significance
}

\author{
Jie Chen ${ }^{1,2}$ \\ ${ }^{1}$ Key Laboratory of Marine Mineral \\ Resources, Guangzhou Marine Geological \\ Survey, Ministry of Land and Resources; \\ ${ }^{2}$ Naval University of Engineering, PLA;
}

\author{
Rongsheng Wan , Jinpeng \\ Zhang, Bin Hang \\ Key Laboratory of Marine \\ Mineral Resources, \\ Guangzhou Marine Geological \\ Survey, Ministry of Land and \\ Resources;
}

\author{
Shilong Su \\ Bureau of Geophysical Prospecting INC. \\ China National Petroleum Corporation)
}

\begin{abstract}
For the first time used the international advanced level of plasma source, acquired seismic section with accuracy better than three meters even within 1 meter, lay the foundation for scientific research, engineering, shallow resources, geological disaster warning and other research. This paper for the first time identified seven seismic reflection interface of Nansha Quaternary, determine that there is acorrespondence between the seismic sequence in range $500 \mathrm{~ms}$ to seabed sediment and three phases of sea level change and the glacial, interglacial periods. With a fine typical seismic structure, confirm that Nansha Quaternary is consistent with global sea level change. Fine shallow seismic structure indicates that the geological phenomenon of Nansha is rich, shallow faults are very developed, should pay attention to faulting caused mudslides and secondary geological disasters.
\end{abstract}

Keywords-quaternary of Nansha; plasma source seismic surveys; seismic sequence; sea-level changes

\section{INTRODUCTION}

The research specifically for the Quaternary of Nansha sea is very little, the gathering seismic data in the past in China is also for the investigation of oil and gas, since the exploration target is to obtain strata position of oil and gas, when the seismic source advantage frequency range used for seismic measurement is 6-50HZ, its resolution is too low for Quaternary shallow layers to obtain effective Quaternary strata structure of Nansha sea area.

The scholars of ASEAN Commission of Petroleum ${ }^{[1]}$ according to sporopollen, planktonic foraminiferal fossil zone, lithologic features, Mat-Zin and Tucker ${ }^{[2]}$ based on the concept of sequence stratigraphy, and Chinese scholars according to the two drilling BAKO-1 and MULU-1 of collected information of Zengmu basin and Beikang basin reclassified Zengmu basin and Beikang basin stratum ${ }^{[4]}$. These results can only determine the bottom boundary of Quaternary but nothing for the inside structure of the Quaternary strata of the Nansha sea area.

Guangzhou Marine Geological Survey in 2013 firstly applied world advanced plasma seismic source into the Nansha sea area to carry out single channel seismic survey, which firstly achieved to use the clear seismic sections to show characteristics of Quaternary seismic strata of Nansha sea area and determined the corresponding relationship between the three sub sequence seismic phases and sea level fluctuation and the glacial. It is of great significance to the research of scientific problems such as Quaternary marine environment change and stratum structure of South China Sea.

\section{SEISMIC SEQUENCE AND FEATURES}

The research area is located in the south of south China Sea, Nansha sea area, there are two main sections, the positions are shown in Fig.1.

These two survey lines start from the continental shelf to the transition of continental slope, A-A' for north to south direction, B-B' for the northeast direction, lines intersection point of two survey is $Q$, the background shows the sea floor topography. Fig. 2 shows the original single channel seismic profiles, end positions $\mathrm{A}$ 'and $\mathrm{B}$ ' are turning points of continent slope and continent shelf.

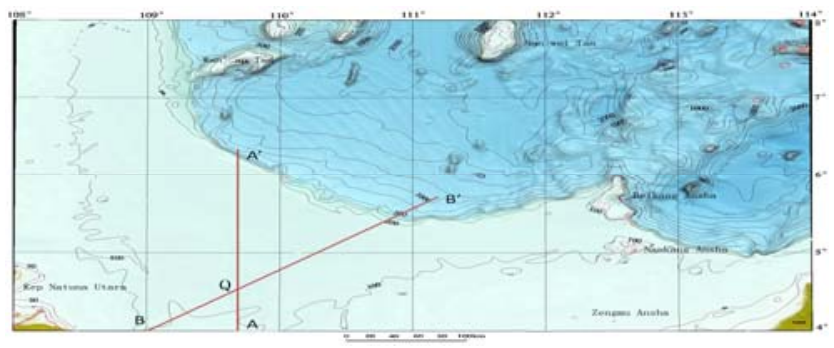

Fig. 1. Measuring line location map

(a)

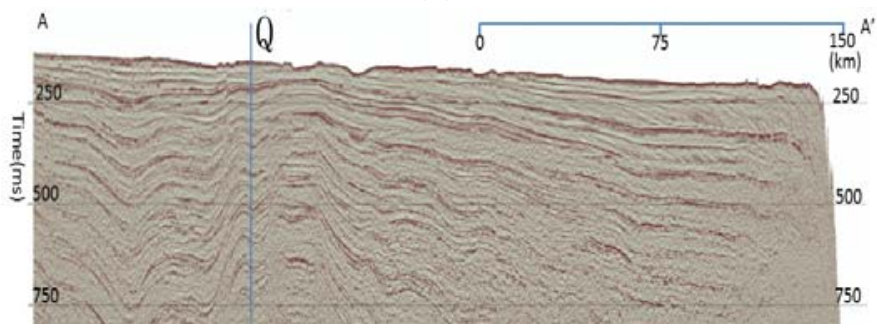

(b) 


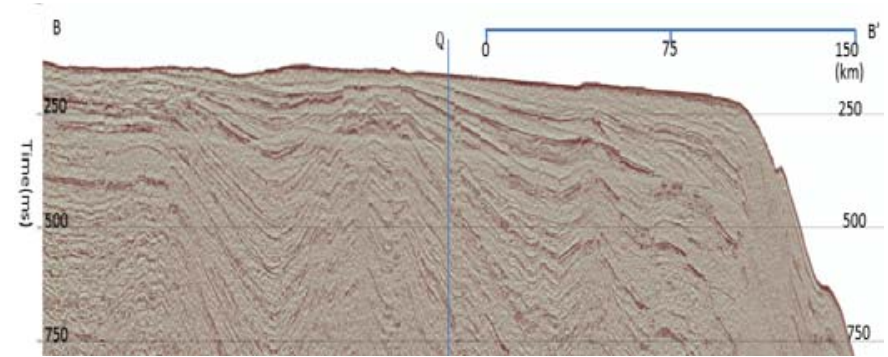

Fig. 2. (a)A-A' single-channel seismic profile; (b) B-B' single-channel seismic profile

According to the single-channel seismic reflection wave group characteristics, identified seven seismic reflection interfaces from the bottom of sea to the bottom of Quaternary , from top to bottom as $\mathrm{R}_{0}, \mathrm{R}_{1}, \mathrm{R}_{2}, \mathrm{R}_{3}, \mathrm{R}_{4}, \mathrm{R}_{5}$ and $\mathrm{R}_{6}$ (Fig.3). Seismic reflection interfaces of continental shelf area is easy to track, continent slope affected by the quality of seismic data is difficult to track, but in the local sag area sequence interfaces are easily identified. Interface distribution for $R_{3}$ 、

$R_{4} 、 R_{5}$ and $R_{6}$ is the most extensive, and $R_{1}$ and $R_{2}$ are the main distribution in continent slope turning zone and continent slope zone.

$\mathrm{R}_{0}$ : undersea seismic reflection interfaces, a high frequency, high amplitude, high continuous, double-phase reflection characteristics, it changes with ups and downs of the seabed, double-phase characteristics are not obvious at fault section and steep continent slope.

$\mathrm{R}_{1}$ : mainly identified in central area of the continental shelf. Generally in a high frequency, medium-high amplitude, high continuous, double-phase reflection characteristics, reflection events are relatively flat, stable on the whole and can achieve continuous tracking .

$\mathrm{R}_{2}$ : mainly identified in the continent shelf area. Above the interface is a set of medium-weak amplitude reflection layer group, below the interface is a set of a medium-strong amplitude reflection layer group.

$\mathrm{R}_{3}$ : mainly identified in the continent shelf area. The reflection of its upper reflection layer group is weak, that of the lower reflection layer group is strong. The overlying strata have obvious downlap phenomenon and the onlap phenomenon can be seen in the vicinity of the interface.

$\mathrm{R}_{4}$ : mainly identified in the continent shelf area, medium frequency, high amplitude, medium-high continuous, multi-phase reflection characteristics. Seismic reflection characteristics are significantly different above and below the interface. Above the interface is for a set of weak amplitude reflection layer group, below the interface is generally a set of strong amplitude reflection layer group, multi-reflection phase characteristics are obvious in most regions.

$\mathrm{R}_{5}$ :mainly identified in the continent shelf area. Seismic reflection characteristics are significantly different, above the interface is for a weak amplitude reflection layer group, below the interface is generally for a strong amplitude reflection layer group, double-phase reflection characteristics are

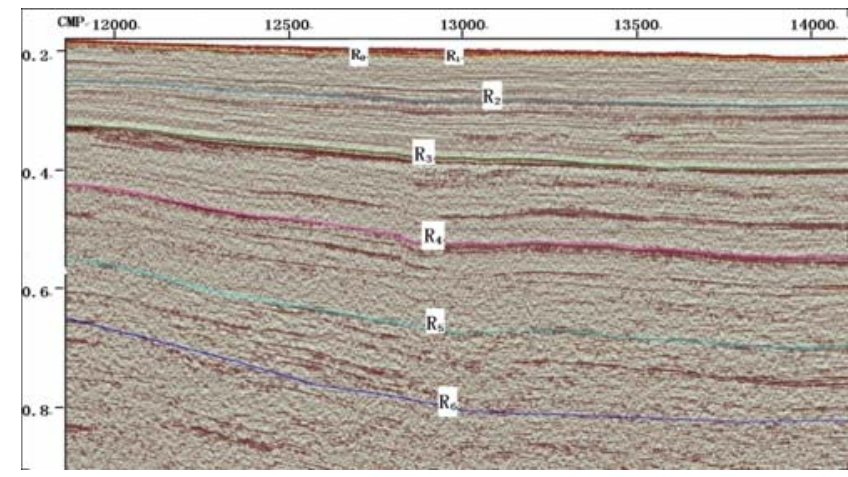

Fig. 3. South China Sea Nansha area seismic sequence and dividing profile

obvious in most regions. Regional downlap phenomenon of the overlying strata is obviously visible, regional onlap phenomenon of the underlying strata is visible near the interface .

$\mathrm{R}_{6}$ : mainly identified in the continent shelf area. Regional double-phase reflection characteristics are significantly different. Continent slope area is with characteristics of medium frequency, medium amplitude and medium continuous reflection, where faulting caused mudslides ,the interfaces in west and south region of work area are buried shallow and with the characteristics of clear structure and easy tracking.

\section{SEISMIC GEOLOGICAL SIGNIFICANCE}

\section{A.The Quaternary Sea-level Change of The Nansha Sea}

The scientific drilling project 1143 can be checked in this area, which latitude is $9^{\circ} 21.72^{\prime} \mathrm{N}$ and longitude is $113^{\circ}$ $17.11^{\prime}$ E. The water depth is 2772 meters and drilling core length is $1101.79 \mathrm{~m}$ that synthesis depth is $516 \mathrm{~m}$ and cross domain 10 million years. So, the Quaternary deep-sea research has a certain reference value. There are about deposition of $100 \mathrm{~m}$ of the Quaternary sediments in two million years at site 1143 . Due to the Quaternary sediment formation rate is not high, sedimentary strata is generally less than 500ms.

Fig.4 shows the detailed interpretation results of the amplification profile in the Nansha waters of the South China Sea A-A' northern section. This section lacks of reflection interface of $R_{1} . R_{2}, R_{3}, R_{4}, R_{5}$ representative of the sub sequence interface, constitute $A_{15}, A_{14}, A_{13}, A_{12}$ sub sequence of the bottom. $R_{2}$ corresponds to the upper Pleistocene ice age bottom boundary, $\mathrm{R}_{3}$ corresponds to the Middle Pleistocene ice age bottom boundary, $\mathrm{R}_{4}$ corresponds to the lower Pleistocene bottom boundary, and $\mathrm{R}_{5}$ corresponds to the lower Pleistocene epoch at the end of the ice age. Each sub sequence consists of three sets of different sub layer composition. II1, III1, IV1, V1 are the bottom layers that have characteristics with no reflection or disorder reflection, II2, III2, IV2, V2 are foreset. The progradational reflection seismic sequence of delta to the sea is development of glacial stage. At this stage, the land outcropping area is largest. I3, II3, III3, IV3 are a stable overlying deposit. The parallel and sub-parallel seismic reflection sequence constitute interglacial main features. 


\section{B.The Change of Seismic Interfaces And Shallow Fracture}

Fig.4 shows the detailed interpretation results of the amplification profile in B-B ' northern section. Seismic faciesis are very rich. In such a depth range of less than $500 \mathrm{~ms}$, A district reflects the old stable sedimentary layer in the structure under the action of the occurrence of folds and bottom area B reflects the river erosion internal for different stages of filling, turbidity or debris flow in high incidence area, area C is piedmont olistostromes. Area D is beveled delta product deposition area, area $\mathrm{E}$ is stable drape deposits and $\mathrm{F}$ region is seaward slope region due to the gravity sliding collapse of the unstable region. It shows that the tectonic evolution of shallow layer is still very complex, and the high resolution seismic profile obtained by the new technology is a prelude to the fine study of Quaternary.

Fig. 5 also shows that this profile shallow fault is very developed and such an interval of less than $80 \mathrm{~km}$ can explain at least 8 faults. The breaking distance is small between F1, F2, F3, F4, F5, F6, F7, F8 and distance is generally not more than $10 \mathrm{~m}$. The fault is still active by slope of the accumulation of sediment to sea gravity tug so that easy to form the geological disaster. So the geological disaster warning needs to attach great importance.

\section{CONCLUSION}

Quaternary research degree is relatively low in the south of the Nansha. So high precision seismic imaging results to the understanding of the shallow seismic geological structure plays a decisive role (1) the international advanced level of plasma source was used for the first time and seismic profile precision is better than $3 \mathrm{~m}$ even within $1 \mathrm{~m}$, will lay the foundation for the study of scientific research, engineering, shallow layer resources, geological disaster warning. (2) the fine seismic geological structure of the Nansha sea area was determined on the basis of high precision seismic imaging for the first time, and the seven seismic reflection interfaces were identified. (3) the sedimentary range of $500 \mathrm{~ms}$ in Nansha sea area has been determined by the typical seismic geological section, at least 3 large sea level rise and fall, each of which is a period of large-scale promotion of the delta. (4) the Quaternary geological phenomena in the Nansha sea area are very rich, and the shallow faults are also very strong. Need to pay attention to the early warning of geological hazards.

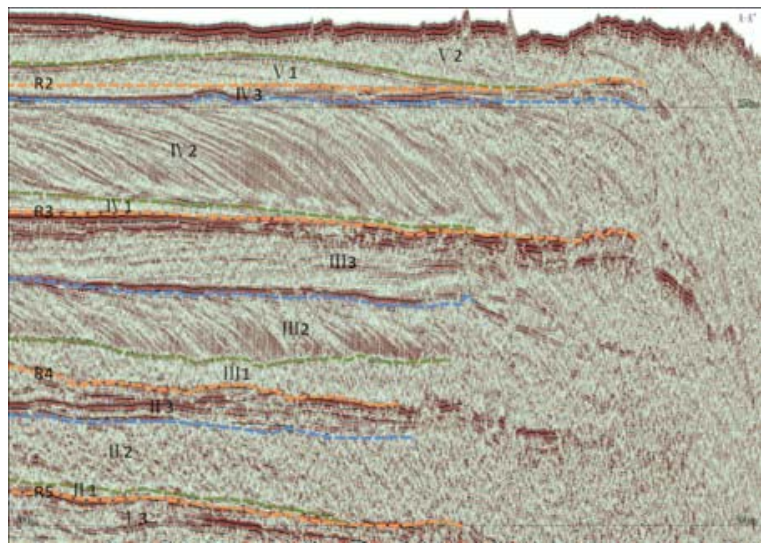

Fig. 4. A-A 'northern section with fine interpretation

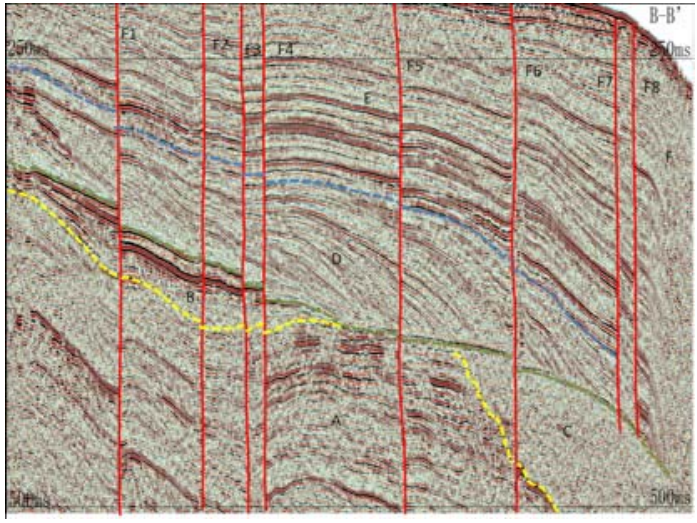

Fig. 5. B-B 'typical northern section with fine interpretation

\section{REFERENCES}

[1] ASCOPE. Tertiary sedimentary basins of the Gulf of Thailand and South China sea: stratigraphy, structure and hydrocarbon occurrences.ASCOPE Secretariat, 1981.

[2] Mat-Zin I.C., Tucker M.E. An alternative stratigraphic scheme for the Sarawak Basin. Journal of Asian Earth Sciences, 1999, 17 (1-2): 215-232. 